\title{
The Effect of an XBOX Kinect Dance Intervention on the Affect of Sedentary University students
}

\author{
RC Gibson', S Roopchand-Martin², G Mason ${ }^{3}$
}

\begin{abstract}
Objective: To explore the effect of a video game dance exercise programme on the affect of sedentary university students.

Method: A one-group pretest post-test design was used. Participants $(n=25)$ completed six weeks of training using the Just Dance 4 disc with the XBOX Kinect 360. The sessions started at 30 minutes of dance five days per week for the first two weeks followed by 45 minutes four days per week for the next two weeks and finishing at 60 minute sessions three days per week for the last two weeks. Affect was assessed pre- and post-intervention using the expanded version of the Positive and Negative Affect Scale (PANAS-X).

Results: There was a significant increase in the general positive affect $(\mathrm{p}=0.02)$ and a significant decrease in the general negative affect $(\mathrm{p}<0.01)$. There was also a significant reduction in all four of the basic negative emotions (fear, $\mathrm{p}=0.03$, hostility, $\mathrm{p}<0.01$; guilt, $\mathrm{p}=0.01$, sadness, $\mathrm{p}<0.01$ ) on the scale whilst two of the three basic positive emotions improved (joviality, $\mathrm{p}<0.01$, self-assurance, $\mathrm{p}=0.02)$. The participants also had significantly less shyness $(\mathrm{p}<$ $0.01)$ and fatigue $(\mathrm{p}<0.01)$ and more serenity $(\mathrm{p}=0.02)$ post intervention.

Conclusion: Videogame-based dance exercise was associated with a statistically significant increase in positive affect and a statistically significant decrease in negative affect among sedentary university students.
\end{abstract}

Keywords: Affect, exercise, videogame

\section{Efecto de una Intervención de Baile Xbox Kinect sobre la Afectividad de Estudiantes Universitarios Sedentarios \\ RC Gibson'1, S Roopchand-Martin², G Mason ${ }^{3}$}

\begin{abstract}
RESUMEN
Objetivo: Explorar el efecto de un programa de ejercicios de baile de videojuegos sobre la afectividad de estudiantes universitarios sedentarios.

Diseño: Se usó un diseño de preprueba y postprueba con un grupo. Los participantes $(n=25)$ completaron seis semanas de entrenamiento usando el disco Just Dance 4 con la consola Xbox Kinect 360. Las sesiones comenzaron con 30 minutos de baile cinco días a la semana durante las dos primeras semanas, seguidas por 45 minutos cuatro dias por semana en las dos semanas siguientes, y terminando con sesiones de 60 minutos tres días por semana durante las últimas dos semanas.
\end{abstract}

From: ${ }^{1}$ Department of Community Health and Psychiatry, ${ }^{2}$ Section of Physical Therapy and ${ }^{3}$ Department of Sociology, Psychology and Social Work, The University of the West Indies, Kingston 7.
Correspondence: Dr RC Gibson, Department of Community Health and Psychiatry, The University of the West Indies, Kingston 7. Email: roger.gibson02@uwimona.edu.jm 
Principales medidas de resultado: La afectividad se evaluó antes y después de la intervención mediante la versión expandida de la Escala de Afectos Positivos y Negativos (PANAS-X).

Resultados: Hubo un aumento significativo en el afecto positivo general $(\mathrm{p}=0,02)$ y una disminución significativa en el afecto negativo general ( $\mathrm{p}<0,01)$. También hubo una reducción significativa de las cuatro emociones básicas negativas (miedo, $\mathrm{p}=0.03$; hostilidad, $\mathrm{p}<$ 0.01; culpa $\mathrm{p}=0.01$; tristeza, $\mathrm{p}<0.01$ ) en la escala, mientras que dos de las tres emociones positivas básicas mejoraron (jovialidad, $\mathrm{p}<0.01$; seguridad en sí mismo, $\mathrm{p}=0.02$ ). Los participantes también tuvieron significativamente menos timidez $(\mathrm{p}<0.01)$ y fatiga $(\mathrm{p}<0.01), y$ más serenidad $(\mathrm{p}=0,02)$ posterior a la intervención.

Conclusión: El ejercicio de baile basado en videojuegos se asoció con un aumento estadísticamente significativo de los afectos positivos y una disminución estadisticamente significativa de los afectos negativos entre los estudiantes universitarios sedentarios.

Palabras clave: Afecto, ejercicio, videojuego

West Indian Med J 2017; 66 (6): 635

\section{INTRODUCTION}

Exergaming (also known as active video-gaming) is a method of inducing full body exercise through the use of video games. This mode of exercise is growing in popularity (1) and many studies have shown that some of these games meet the requirements for mild-to-moderate intensity exercise as outlined by the American College of Sports Medicine (2-11). It is, therefore, possible that engaging in some exergaming activities might yield health benefits similar to those associated with traditional physical exercise.

The exploration of this possibility is important given the rising popularity of exergaming (1) and the low level of adherence by the general population to exercise recommendations $(12,13)$. The estimates of physical inactivity range from four to $84 \%$ in developed countries and 17 to $91 \%$ in developing ones $(12,13)$. In Jamaica, a developing country, $43 \%$ of females between the ages of 15 and 74 years were reported to be physically inactive (14). If exergaming yields health benefits, then its popularity could make it an enticing option of physical exercise.

The possible health benefits to be derived from exergaming would include those that have been found to be associated with physical exercise in general. Areas of health that have been explored for an association with physical exercise have included both physical (12) and mental health (15-19). Regular physical exercise has been clearly associated with benefits for the cardiovascular, musculoskeletal and neuromuscular systems (12). This has resulted in a position statement by the American College of Sports Medicine (ACSM) which recommends that adults who have no medical contraindication engage in moderate-intensity aerobic physical activity for a minimum of 30 minutes a day, five days per week, or vigorous-intensity aerobic activity for 20 minutes a day, three days per week in order to maintain their physical fitness and health (12).

Whilst the physical benefits of exercise are well documented, reports on its psychological effects are not as clear (15). Researchers have explored various parameters of the psychological outcomes of physical activities, some of which are the interrelated concepts of depression $(17,20)$, mood $(18,19)$ and affect $(21,22)$. All the three concepts address varying aspects of emotional well-being which has been found to be an important component of overall wellness (23). Of these psychological foci, affect gives the most holistic insight into the individual's lived experiences. Unlike depression, which refers to the experience of sustained low mood and other accompanying symptoms such as diminished interest and energy (24), affect is broader as it encompasses both positive and negative experiences. Likewise, affect entails more of the complexities of shifting emotional responses rather than focussing on a dominant emotional tone as is the case for mood. Affect refers to the more immediate and often situational emotional experience of individuals as compared to mood which connotes an overall and more or less sustained feeling state (25). Therefore, an exploration of affect allows a deep and complex appreciation of an individual's internal emotional experiences. Frequent experiences of positive affect have been linked to confidence, optimism, effective coping and physical well-being (26). Therefore, people's experiences that 
enhance their positive affect are the harbingers of their emotional and physical wellness.

As for other psychological outcomes, research on the impact of physical activities on affect has been inconsistent. Studies on acute exercise and affect have demonstrated that high intensity exercise leads to an increase in negative affective states whilst lower intensity exercise is associated with more positive affect $(15,21,27,28)$. In contrast, regular physical activities have been shown to be associated with positive affect (22). Besides the considerations of the type of exercise (acute or regular) and exercise intensity, other contextual issues of physical activities are believed to mediate their effect on affect. One example is the extent to which personal goals related to exercise activities are set and achieved (29). Another is the presence of social engagement while participating in physical activities (22). For example, the relationships and support systems that may develop through the social interactions in the context of group physical activities have been identified as one of the possible mechanisms through which physical activity may have an impact on people's psychological parameters (16).

Compared with traditional physical exercise, fewer studies have looked at the psychological effects, including affect, of exergaming. Russell and Newton (30) compared a single session of an interactive video game cycle ergometer exercise, traditional cycle ergometer exercise and playing a sedentary video game. They found that there were equal improvements in positive affect for both exercise groups whilst the group that played the sedentary video game had an increase in negative affect (30). In contrast, Douris et al (3) found that an acute bout of exergaming led to a decreased positive psychological well-being in young adults immediately after the gaming experience compared to the traditional exercise. No studies were identified which explored the impact of regular sessions of exergaming on affect. There is therefore, no consensus on the effect of acute exergaming on affect and a dearth of investigations on the effect of regular exergaming on affect. In the current study, we attempted to focus on the latter issue.

While the observation of lower than recommended physical activity levels holds for all ages, college students are a group for concern since their health status will determine the future burden on healthcare systems. Data in the United States of America have shown that approximately $51 \%$ of college students did not meet the minimum recommended levels of the physical activities for health benefits (31). The rate appears to be even higher in Jamaica as approximately $70 \%$ of the students surveyed at a major university exercised at levels below this minimum (32). Therefore, for our study, we focussed on sedentary university students and assessed the effect of six weeks of videogame-based dance training on their affect. We hypothesized that pre- and post-intervention comparisons would show this form of physical activities leading to an increased positive affect and a reduced negative affect. Such a finding would imply that regular exergaming could be an effective method of enhancing individuals' general well-being.

\section{METHODS}

\section{Data collection procedure and design}

A one-group pre-test post-test experimental design was used to meet the objectives of this study after approval was obtained from the Ethics Committee of The University of the West Indies, Faculty of Medical Sciences, Mona. The participants were assigned subject numbers and one- week prior to the start of training the baseline assessments for their weights, heights and affect were obtained. The exercise programme was conducted in an indoor, air conditioned research laboratory located at the university.

The XBOX Kinect 360 video-game console was used. It utilizes a camera to detect the player's motion. There are several active games designed for this system; however, of particular interest for this study was the Just Dance 4 disc which allows the participants to engage in dance exercise as they follow the moves of a virtual instructor. During the gameplay, the participants are provided with ongoing intrinsic feedback which includes: visual, auditory, vestibular and somatosensory inputs. Extrinsic feedback is also provided as the participants can view their scores, as well as that of other players, immediately on the completion of each dance. During the dances, is also visual feedback which indicated how well one has mastered each dance move. The participants could engage in play on an individual basis or in small groups of up to four persons. The set-up of the gaming system allows the participants to set goals related to mastery of the dance moves.

The XBOX Kinect 360 system was connected to a multimedia projector and the images projected onto a screen that was 3.5 metres wide and 2.5 metres high. The participants were constrained to dancing in a space that was 3.5 metres by five metres. The camera for the Kinect system was placed directly in front of the participants so that their movements could be picked up and 
the feedback on their performance could be provided by the gaming system. The Just Dance 4 disc was used for the intervention. The 'shuffle' mode was utilized which allowed for the gaming system to randomly select songs and maintain continuous play with no interruptions.

Given that all the participants were assessed as sedentary, the time for the activity increased gradually over the intervention. For the first two weeks, the subjects were required to participate in only 30 minutes of dance in small groups of two to four subjects, five days per week (the equivalent of 150 minutes per week). This was deemed appropriate given the participants' youth and health-status. The time was increased to $180 \mathrm{~min}-$ utes per week for week-three onwards. For weeks three and four, their activity consisted of 45 minutes of dance, four days per week, and for weeks five and six, it was 60 minutes of dance, three days per week. The number of sessions, although not the overall exercise time, was reduced from week-four onwards in order to better accommodate the participants' academic schedules. During each session, their aerobic requirements ranged from mild-to-moderate. The subjects were asked to keep-up with the dances as best as they could. If they needed a break they were told to just march on the spot until they could resume dancing.

\section{Participants}

The participants were recruited from the student population of the University through the classroom presentations done by one of the researchers. A sample of convenience was used whereby, the first 32 participants who met the criteria for participation, were included. This number represented an over-sampling of the population of interest in order to safeguard against the possible attrition of the participants. Sample size calculations had indicated that, based on the paired $t$-test with a two-sided alpha of 0.05 , a sample size of 26 would have been sufficient to demonstrate an effect size of 0.8 with statistical power of $80 \%$ (33).

The participants were included if they were aged 18 to 30 years; if their activity level over the previous six weeks was below the minimum recommendation of the ACSM and they were not engaged in aerobic exercise on a regular basis (ie, three days per week for the last six weeks); if they were deemed healthy to exercise according to the physical activity readiness questionnaire (PAR-Q); and if they gave written consent to participate. The participants with any orthopaedic injuries for which dancing was a contraindication were excluded. Also excluded were persons with symptomatic cardiopulmonary conditions including: asthma, persons with rheumatological and neurological disorders and balance or visual impairments.

Twenty-five of the 32 participants completed the study. The main reason for withdrawal from the study was the competing demands with their academic activities related to their course of study at the university. The majority of the sample was females $(92 \%)$; the mean age was 21.04 years $(\mathrm{SD}=2.38$ years); and the mean body mass index was 25.78 ( $\mathrm{SD}=$ 5.87). All the participants were enrolled in the same programme of study in the Faculty of Medical Sciences but were from different year groups.

\section{Measures}

Affect was assessed with the positive and negative affect scale expanded form [PANAS-X] (34). The instrument consists of 60 -word items that describe different feelings and emotions. The participants were asked to rate the degree to which they had each of the feelings described in the previous week. Rating was done on a five-point Likert scale ( 1 = very slightly or not at all, $5=$ extremely). Specific items were summed up to produce 13 subscale scores. These included the scores for general negative affect, general positive affect, basic negative emotions (fear, hostility, guilt, sadness), basic positive emotions (joviality, self-assurance, attentiveness) and other affective states (shyness, serenity, fatigue, surprise). Higher scores indicated a greater level of the affective state relevant to the subscale.

The reliability coefficients (coefficient alphas) for both the general positive affect and general negative affect subscales have been found to be high, with values ranging from 0.85 to 0.90 on the former and from 0.83 to 0.90 on the latter (34). The coefficient alphas obtained from the baseline assessment of the participants' affect in the current study were 0.87 for the general negative affect subscale and 0.88 for the general positive affect subscale. A fair level of validity has been inferred from the high positive correlations of the original negative affect subscale with measures of distress, dysfunction and depression as well as the negative correlations of the original positive affect subscale with these measures (35).

\section{Statistical analyses}

Mean scores for each subscale were calculated and the paired $t$-test was used to determine whether there were significant changes in the subjects' affect. All the statistical analyses were conducted with the statistical package for the social sciences [SPSS] (Version 18). 


\section{RESULTS}

At the end of the six-week intervention, there was a significant increase in the general positive affect $(p=0.02)$ and a significant decrease in the general negative affect $(p<0.01)$ [Table 1].

Table 1: Changes in positive and negative affect scale expanded form scores after dance exercise training with XBOX kinect

\begin{tabular}{lcccr}
\hline PANAS-X subscale & $\begin{array}{c}\text { Mean change } \\
\text { (final - initial } \\
\text { score) }\end{array}$ & SD & 95\% CI & $\boldsymbol{p}$ \\
& -4.28 & 5.37 & $-6.49--2.07$ & $<0.01$ \\
\hline General negative affect & 2.88 & 5.68 & $0.53-5.23$ & 0.02 \\
General positive affect & & & & \\
Basic negative emotion & -1.36 & 2.93 & $-2.57--0.15$ & 0.03 \\
Fear & -3.36 & 3.89 & $-4.97--1.75$ & $<0.01$ \\
Hostility & -2.64 & 4.54 & $-4.51--0.77$ & 0.01 \\
Guilt & -3.44 & 4.52 & $-5.31--1.57$ & $<0.01$ \\
Sadness & & & & \\
Basic positive emotion & 3.24 & 4.68 & $1.31-5.17$ & $<0.01$ \\
Joviality & 1.96 & 4.04 & $0.29-3.63$ & 0.02 \\
Self-assurance & 0.04 & 2.35 & $-0.93-1.01$ & 0.93 \\
Attentiveness & & & & \\
Other affective states & -2.2 & 2.78 & $-3.35--1.05$ & $<0.01$ \\
Shyness & 1.32 & 2.75 & $0.19-2.45$ & 0.02 \\
Serenity & -3.76 & 5.23 & $-5.92--1.60$ & $<0.01$ \\
Fatigue & -0.08 & 3.00 & $-1.32-1.16$ & 0.90 \\
Surprise & & & & \\
\hline
\end{tabular}

PANAS-X: The Positive and Negative Affect Schedule; SD: standard deviation

There was also a significant reduction on all of the basic negative emotion subscales: (fear, $p=0.03$; hostility, $p$ $<0.01$, guilt, $p=0.01$ and sadness, $p<0.01$ ). For the basic positive emotion subscales, there were significant increases in joviality $(p<0.01)$ and self-assurance $(p=$ $0.02)$ scores, but no change in attentiveness. There was significantly less shyness $(p<0.01)$ and fatigue $(p<$ $0.01)$ at the end of the six weeks and significantly more serenity $(p=0.02)$. There was no significant change in the surprise scores.

\section{DISCUSSION}

Among the literature on exergaming and affect, the methodology of the current study is unique because of its focus on regular exergaming activity, as most of the previous research considered only single sessions of exergaming activity. In addition, both before and after the six-week intervention, the participants reported on their affective experiences over the preceding week, thus, giving a perspective on their sustained effect of regular physical exercise on their affect, as opposed to the more immediate effects typically probed in previous research. When the measures at the baseline and after six weeks of regular exergaming were compared, the participants had significantly higher levels of positive affect and significantly lower levels of negative affect after the exposure to regular exergaming. This is suggestive of the sustained mental health benefits they derived from the structured and regular participation in exergaming. This modality of physical exercise may therefore, represent an important option for promoting mental health and wellness, especially among youths given the prevailing popularity of this activity among this population.

The increases in positive affect and decreases in negative affect which were observed are highly desirable given the broader implications for quality of life and general well-being (26). Although the observed association between positive affect and exergaming may seem intuitive and entirely predictable, it is important to bear in mind that the seemingly intuitive linkage between physical exercise and affect has not always been borne out in research. This is illustrated by a previous study on exergaming (3) which found an associated decrease in positive affect. Of note, the design of that study allowed the measurement of affect only immediately after a single session of exergaming, as opposed to after several weeks of regular exergaming as in the current study. Although strong inferences cannot be made on the basis of these two studies in isolation, together their findings suggest the possibility that in the short term, ie after a single session, exergaming may sometimes result in a decrease in positive affect but in the long term an increase in positive affect is more likely.

These temporal differences in affective changes may be related to the gradual mastery of the specific motor skills necessary for the successful execution of the exergaming programmes. Initially, there might be a decrease in positive affect because of challenges with acquiring new skills. However, subsequently this may give way to an increase in positive affect as these new skills are mastered. The instant feedback provided to exergaming participants is likely to greatly facilitate their modelling and acquisition of new motor skills. Thus, exergaming, in comparison with conventional methods of physical exercise may; promote more rapid learning, leading to a greater sense of achievement and consequently to higher levels of positive affect.

The extent to which our hypothesis about temporal differences in affective changes related to exergaming is true, can only be determined with further research. The same is true for determining what other specific 
elements of the complex phenomenon of exergaming might contribute to the observed increases in positive affect. Some possibilities are potential mediating factors identified by previous research on traditional exercise such as the intensity of the exercise (15) and the level of social engagement with which the activity is associated (22). Based on our own observations of the participants of this study, social engagement assessment could include the level of camaraderie among exergamers and the sense of competition which exergaming as a group activity might engender. Identifying these factors would help in informing the recommendations for participation in physical activity to confer mental health benefits.

It is tempting to conclude that the overall experience of exergaming in a group has well-defined mental health benefits. However, caution must be taken with this interpretation of the findings of the study. Not all exergaming programmes will have the same combination of factors that might be mediating the production of a positive affect. For example, the "Free Run" programme used in the research of Douris et al (3) provides a different kind of experience from the dancing programme used in the current study. This is, in fact, also another possible explanation for the difference in the findings between these two studies. It also underlines the need to be circumspect in formulating conclusions about exergaming based on the findings related to a specific type of activity from a very heterogeneous group of game programmes.

On the basis of our findings, and the identified limitations, the way forward with further research should incorporate appropriate comparison groups (eg persons engaging in conventional physical exercise, exergaming outside of a group setting and participating in different modalities of exergaming). In the interim, it would appear that regularly scheduled dance-based exergaming group activities are associated with positive affect and should be a useful strategy for enhancing mental and general well-being.

\section{CONCLUSION}

This study has shown that a group-based active videogaming exercise training programme can have a positive impact on the affect of sedentary university students.

\section{ACKNOWLEDGEMENTS}

The authors would like to acknowledge the physical therapy students who assisted in monitoring the training programme.

\section{REFERENCES}

1. Entertainment Software Association. Essential facts about the computer and video gaming industry 2014: Sales, demographic and usage data. 2014. [updated 2014 April; cited 2014 Aug 5]. Available from: http:// www.theesa.com/facts /pdfs/esa_ef_2014.pdf

2. Bosch RP, Peloni J, Thornton A, Lynskey JV. The heart rate response to Nintendo Wii Boxing in young adults. Cardiopulm Phys Ther J 2012; 23: 13-29. Available from: http://cpptjournal.org/pdfs/members/fulltext/2012/june/Heart Rate.pdf

3. Douris PC, McDonald B, Vespu F, Kelley NC, Herman L. Comparison between Nintendo Wii Fit aerobics and traditional aerobic exercise in sedentary young adults. J Strength Cond Res 2012; 26: 1052-7.

4. Graf DL, Pratt LV, Hester CN, Short KR. Playing active video games increases energy expenditure in children. Pediatrics 2009; 14: 532-40.

5. Hurkmans HL, Van den Berg-Emons RJ, Stam HJ. Energy expenditure in adults with cerebral palsy playing Wii Sports. Arch Phys Med Rehabil 2010; 91: 1577-81.

6. McWha JA, Brown GA. Effects of energy expenditure while playing the Nintendo Wii against a human and a computer opponent [Internet]. Kearney (NE): University of Nebraska, Human Performance Laboratory HPERLS Dept; 2012 [updated 2012; cited 2013 May 4]. Available from http://www.unk.edu/uploadedFiles/academics/gradstudies/ssrp/ McWha\%20Paper\%202008\%20SSRP.pdf

7. Mellecke RR, McManus AM. Energy expenditure and cardiovascular responses to seated and active gaming in children. Arch Pediatr Adolesc Med 2008; 162: 886-91.

8. Miyachi M, Yamamoto K, Ohkawara K, Tanaka S. METs in adults while playing active videogames: A metabolic chamber study. Med Sci Sports Exerc 2010; 42: 1149-53.

9. O'Donovan C, Hussey J. Active video games as a form of exercise and the effect of gaming experience: A preliminary study in healthy young adults. Physiotherapy 2012; 98: 205-10.

10. Worley JR, Rogers SN, Kraemer RR. Metabolic responses to Wii Fit video games at different game levels. J Strength Cond Res 2011; 25 (Suppl 3): 689-93.

11. Willems HL, Bond TS. Metabolic equivalent of brisk walking and playing new generation active computer games in young adults. Medicina Sportiva 2009; 13: 95-8.

12. Garber CE, Blissmer B, Deschenes MR, Franklin BA, Lamonte MJ, Lee IM et al. Quantity and quality of exercise for developing and maintaining cardiorespiratory musculoskeletal and neuromotor fitness in apparently healthy adults: Guidance for prescribing exercises. Med Sci Sports Exerc 2011; 43: 1334-59.

13. Oldridge NB. Economic burden of physical inactivity: Healthcare costs associated with cardiovascular disease. Eur J Cardiovasc Prev Rehabil 2008; 15: 130-9.

14. Tulloch-Reid MK, Younger NO, Ferguson T, Francis DK, Abdulkadri $\mathrm{AO}$, Gordon-Strachan GM et al. Excess cardiovascular risk burden in Jamaican women does not influence predicted 10 -year CVD risk profiles of Jamaica adults: An analysis of the 2007/08 Jamaica Health and Lifestyle Survey. PLOS ONE 2013; 8 (Suppl 6): e66625.

15. Ekkekakis P, Petruzzello SJ. Acute aerobic exercise and affect. Sports Medicine 1999; 28: 337-74.

16. Peluso MAM, de Andrade LHSG. Physical activity and mental health: The association between exercise and mood. Sao Paulo Clinics 2005; 60: $61-70$.

17. Babyak M, Blumenthal JA, Herman S, Khatri P, Doraiswamy M, Moore $\mathrm{K}$ et al. Exercise treatment for major depression: Maintenance of therapeutic benefit at 10 months. Psychosom Med 2000; 62: 633-8.

18. Hansen CJ, Stevens LC, Coast JR. Exercise duration and mood state: How much is enough to feel better. Health Psychol 2001; 20: 267-75.

19. Lee RE, Goldberg JH, Sallis JF, Hickmann SA, Castro CM, Chen AH. A prospective analysis of the relationship between walking and mood in sedentary ethnic minority women. Women Health 2001; 32 (Suppl 4): $1-15$.

20. Smith PJ, Blumenthal JA, Babyak MA, Georgiades A, Hinderliter A, Sherwood A. Effects of exercise and weight loss on depressive 
symptoms among men and women with hypertension. J Psychosom Res 2007; 63: 463-9.

21. Bixby WR, Spalding TW, Hatfield BD. Temporal dynamics and dimensional specificity of the affective response to exercise of varying intensity: Differing pathways to a common outcome. J Sport Exerc Psychol 2001; 23: 171-90. [updated 2001 September; cited 2014 Sep 28]. Available from http://www.humankinetics.com/AcuCustom/ Sitename/Documents/DocumentItem/1064.pdf

22. Pasco JA, Jacka FN, Williams LJ, Brennan SL, Leslie E, Berk M. Do not worry, be active: Positive affect and habitual physical activity. Aust N Z J Psychiatry 2011; 45: 1047-52.

23. Stewart-Brown S. Emotional wellbeing and its relation to health: Physical disease may well result from emotional distress. Br Med J 1998; 317: 1608-9.

24. American Psychiatric Association. Diagnostic and Statistical Manual of Mental Disorders, $5^{\text {th }}$ ed. Arlington, VA: American Psychiatric Association; 2013.

25. Casey P, Kelly B. Fish's clinical psychopathology, $3^{\text {rd }}$ ed. London, UK: Gaskell; 2007.

26. Lyubomirsky S, King L, Diener E. The benefits of frequent positive affect: Does happiness lead to success? Psychol Bull 2005; 131: 803-55.

27. Hall EE, Ekkekakis P, Petruzzello SJ. The affective beneficence of vigorous exercise revisited. B J Health Psychol 2002; 7: 47-66.
28. Kilpatrick M, Kraemer R, Bartholomew J, Acevedo E, Jarreau D. Affective responses to exercise are dependent on intensity rather than total work. Med Sci Sports Exerc 2007; 39: 1417-22.

29. Kerr JH, Kuk G. The effects of low and high intensity exercise on emotions, stress and effort. Psychol Sport Exerc 2001; 2: 173-86.

30. Russell WD, Newton M. Short-term psychological effects of interactive video gaming technology exercise on mood and attention. Educational Technology and Society 2008; 11: 294-308. [updated 2008; cited 2014 Sep 28]. Available from: http://www.ifets.info/journals/11_2/21.pdf

31. American College Health Association. National College Health Assessment II: Reference Group Executive Summary Spring 2013. Hannover, MD: American College Health Association; 2013.

32. Anglin-Brown B, Mullings J, Wilks R, Younger N, Redwood-Kiddoe A, Foster Williams K et al. Physical activity levels among students on The University of the West Indies, Mona Campus. West Indian Med J 2012; 61 (Suppl 6): 35-6.

33. Portney LG, Watkins MP. Foundations of clinical research applications to practice, $2^{\text {nd }}$ ed. New Jersey, NJ: Prentice Hall Health; 2000.

34. Watson D, Clark LA. Manual for the positive and negative affect schedule - expanded form. Iowa City, IA: The University of Iowa; 1994.

35. Watson D, Clark LA, Tellegen A. Development and validation of brief measures of positive and negative affect: The PANAS scales. J Pers Soc Psychol 1988; 54: 1063-70. 